The Journal of

Obstetrics and

Gynaecology
Journal of Obstetrics and Gynaecology

ISSN: 0144-3615 (Print) 1364-6893 (Online) Journal homepage: http://www.tandfonline.com/loi/ijog20

\title{
Knowledge and attitudes of female university students on menstrual cycle and contraception
}

\section{Márta Szűcs, Tamás Bitó, Csaba Csíkos, Andrea Párducz Szöllősi, Cristian}

Furau, Iolanda Blidaru, Aleksandra Kapamadzija, Katarina Sedlecky, György Bártfai \& on behalf of The Scientific Group of the collaborating centres

To cite this article: Márta Szűcs, Tamás Bitó, Csaba Csíkos, Andrea Párducz Szöllősi, Cristian Furau, lolanda Blidaru, Aleksandra Kapamadzija, Katarina Sedlecky, György Bártfai \& on behalf of The Scientific Group of the collaborating centres (2017) Knowledge and attitudes of female university students on menstrual cycle and contraception, Journal of Obstetrics and Gynaecology, $37: 2,210-214$

To link to this article: http://dx.doi.org/10.1080/01443615.2016.1229279

\section{Published online: 06 Dec 2016.}

Submit your article to this journal $\pi$

Џ Article views: 58

Q View related articles ¿

View Crossmark data $₫$ 


\title{
Knowledge and attitudes of female university students on menstrual cycle and contraception
}

\author{
Márta Szűcs a , Tamás Bitóa ${ }^{a}$ Csaba Csíkos ${ }^{b}$, Andrea Párducz Szöllősi ${ }^{c}$, Cristian Furau ${ }^{d}$, lolanda Blidaru ${ }^{\mathrm{e}}$, \\ Aleksandra Kapamadzija ${ }^{f}$, Katarina Sedlecky ${ }^{g}$, and György Bártfai ${ }^{a}$; on behalf of The Scientific Group of the \\ collaborating centres
}

\begin{abstract}
${ }^{a}$ Department of Obstetrics and Gynaecology, University of Szeged, Hungary; ${ }^{b}$ Institute of Education, University of Szeged, Hungary; ${ }^{c}$ Institute of Health Science and Environmental Health, Szent István University, Gyula, Hungary; "“`Vasile Goldis” Western University of Arad, Arad,

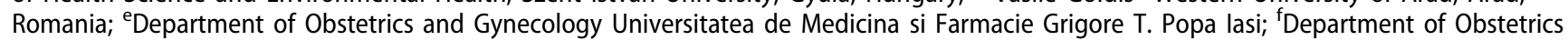
and Gynaecology, Clinical Centre Vojvodine and Medical Faculty, University of Novi Sad, Serbia; ${ }^{9}$ Family Planning Centre, Institute for Mother and Child Health Care of Serbia, Belgrade, Serbia
\end{abstract}

ABSTRACT

Socioeconomic changes, as well as the development of new contraceptive modalities may influence women's preferences in the selection of a method of contraception. The aim of this study was to evaluate the knowledge, opinions and attitudes of female university students regarding the menstrual cycle, sexual health and contraception. A questionnaire-based survey was conducted among 2572 female university students in Hungary, Romania and Serbia, between November 2009 and January 2011. A higher proportion of students of health sciences than students of other faculties had appropriate knowledge of the fertile period within a menstrual cycle: $86.0 \%, 71.5 \%(p=.02)$ and $61.1 \%$ vs. $71.9 \%(p<.001)$, $59.8 \%$ and $43.2 \%(p<.001)$ in Hungary, Romania and Serbia, respectively. Overall, more than $69 \%$ of the female university students believed in the need for monthly menstruation in order to be healthy; however, merely 30 to $40 \%$ of them wished to have monthly bleeding. In general, the respondents were aware of the importance of menstruation in relation to sexual health; however, they wished to suppress the menstruation-related symptoms. Differences in the knowledge and attitudes of female university students of the three assessed countries may be explained in part by cultural differences, and in part by the nature of their studies.

\section{KEYWORDS}

Knowledge of fertile period; family planning; continuous hormonal contraception; green contraceptive methods; suppress menstruation; women's reproductive health

\section{Introduction}

There have been a number of studies published on the knowledge and attitudes related to the menstrual cycle, child-bearing and contraception in different populations, but there have been none in South Eastern Europe recently (Inandi et al. 2003; Tyden et al. 2006; Fruzetti et al. 2008; Merki-Feld et al. 2014). There is a lack of relevant studies in the scientific databases, including Medline and Scopus concerning the three countries involved in the present survey: Hungary, Romania and Serbia. Previous surveys in women of reproductive age regarding their menstrual bleeding patterns have revealed that women in different countries in Europe share similar views about the 'necessity' of menstruation, with approximately $30 \%$ of the responders preferring not having menstrual bleeding at all (Tyden et al. 2006; Fruzetti et al. 2008; Merki-Feld et al. 2014). Students in the present three countries are of particular interest as the availability of contraceptive methods prospered in this region in the last 20 years. There has been a demographic change as the Eurostat study revealed: the 20-year-old population and the age at first childbirth increased (Eurostat 2015). These socioeconomic changes including the proportion of women with higher education, and the generally observed decrease in the number of planned children, have great influence on the preference for contraceptive method (Bjelica 2008).

The aim of this study was to evaluate the knowledge of female university students about the fertile period within a menstrual cycle, their opinion on the importance of menstruation with regard to health and their attitudes related to contraception. Our further aim was to assess the possible differences and the impact of the nature of studies in the examined regions of the different countries concerning the knowledge and attitudes of students on menstruation and contraception.

\section{Materials and methods}

This questionnaire-based study was conducted among female university students in three neighbouring countries: Hungary, Romania and Serbia, between November 2009 and January 2011. The cross-border study was carried out in Gyula and Szeged, Hungary; Arad and lasi, Romania; and Belgrade and Novi Sad, Serbia.

Sample selection was determined by the Department of the Hungarian Central Statistical Office, Szeged for each

CONTACT Márta Szúcs, MD. szmart81@gmail.com @ Department of Obstetrics and Gynaecology, University of Szeged, 1 Semmelweis Str. 6725 Szeged, Hungary 
centre. On the basis of the total number of the female students, the statisticians calculated the necessary numbers of participants in the study in every faculty and class involved in the survey, in Gyula, every second; in Arad and Szeged, every sixth; in lasi, every ninth; and in Belgrade and Novi Sad, every tenth female student was invited to participate.

The questionnaire was completed by the students during lectures. The dean and teachers of the participating faculties were contacted prior to the survey, and they had given their permission for the students to be interviewed in the course of lectures. The course lecturer introduced the person responsible for the questionnaire, who gave a brief explanation on the background of the questionnaire study and the nature of the questionnaire, and requested the students to participate. Only those who wished to participate received the questionnaire. During the completion of the questionnaire, the seating arrangement remained the usual. Completion of the questionnaire required about $15 \mathrm{~min}$. After completion, the students inserted the anonymous questionnaire and the signed consent form in separate collecting-boxes. After collecting the questionnaires, data were processed by the co-workers of the Department of the Hungarian Central Statistical Office, Szeged.

The following questions were asked in the survey: 'On which days between two menses are you most prone to become pregnant?' (knowledge of the fertile period within a menstrual cycle); 'Do you have any abnormality associated with your menstrual cycle?, 'Have you ever been on the sick list because of your symptoms during menstruation?, 'If you could decide, how often would you choose to have menstruation?', 'Why would you prefer fewer periods?', 'Do you think that a method that interferes with your menstrual cycle could be harmful to your future fertility?' (opinions on the importance of menstruation with regard to health); 'What do you think about oral contraception?', 'What kind of contraceptives do you regularly use?', 'Would you be interested in using a daily, low-dose, hormonal combined oral contraceptive, which involves no pill-free interval, and which would allow you to suppress menstruation as long as you need, knowing that this would not have harmful effects?' (attitudes related to contraception).

The study protocol was approved by the local ethics committee at each participating centre. The sample consisted of 2572 students. Their distribution with respect to the country of origin and the nature of their studies are shown in Table 1. The participants were divided into two groups: students of health sciences and students of other faculties, resulting in comparable sample sizes of 1148 (44.6\%) and 1424 (55.4\%), respectively.

The questionnaire comprised a total of 33 questions concerning the menstrual period and related complaints, attitudes to child-bearing (including the optimum age) and

Table 1. Subgroups of participants by countries and faculties.

\begin{tabular}{lccr}
\hline & $\begin{array}{c}\text { Students of } \\
\text { health sciences }\end{array}$ & $\begin{array}{c}\text { Students of } \\
\text { other faculties }\end{array}$ & \multicolumn{1}{c}{ Total } \\
\hline Hungary & $277(10.8 \%)$ & $291(11.3 \%)$ & $568(22.1 \%)$ \\
Serbia & $408(15.9 \%)$ & $490(19.1 \%)$ & $898(34.9 \%)$ \\
Romania & $463(18.0 \%)$ & $643(25.0 \%)$ & $1106(43.0 \%)$ \\
Total & $1148(44.6 \%)$ & $1424(55.4 \%)$ & 2572 \\
\hline
\end{tabular}

requirements concerning contraception, particularly those involving reproductive health.

The questionnaire was presented in equivalent form in the language of the country involved, i.e. Hungarian, Romanian and Serbian. The questions were discussed in English and Hungarian (as some of the co-investigators in Romania and Serbia are fluent speakers of Hungarian), and translated to the native language of the participating countries. The study was pilot tested in 20-20 female students of health sciences and students of other faculties in all centres to evaluate the intelligibility of the questionnaire.

The following groups of variables were included in the analyses:

- Demographic or background variables: age, country, nature of university studies, type of residence, marital status and data about the menstrual cycle (period, length, complaints and use of contraceptives).

- Knowledge-related variables: the necessity of menstruation, and the most fertile period of the cycle.

- Variables related to attitudes (the intention to use an oral contraceptive to suppress bleeding for a long time, and the preferred frequency of menstruation).

The statistical analysis was performed in Hungary, using descriptive statistics, contingency coefficients, correlations (Spearman's correlations), statistical comparisons (two-way ANOVA), and conducted with the SPSS software (C) IBM Corporation, Szeged, Hungary). The level of statistical significance was set at $5 \%$.

\section{Results}

The total number of volunteer participants was 2572 with the following distribution: 1106 (43.0\%), 898 (34.9\%) and 568 $(22.1 \%)$ in Romania, Serbia, and Hungary, respectively (Table 1). The ratio of students of health sciences and students of other faculties in Romania, Serbia and Hungary was similar: $58.1 \%$ vs. $41.9 \%, 54.6 \%$ vs. $45.4 \%$ and $51.2 \%$ vs. $48.8 \%$, respectively. The answer rates in the questionnaire were amply sufficient for data analysis (ranging from $94 \%$ to 99\%); the data relating to missing values are shown in the corresponding analyses. The mean age of the examined population was 22.2 years (18-28).

\section{Knowledge on the menstrual cycle}

One item in the questionnaire addressed the students' rather trivial factual knowledge about the fertile period within a menstrual cycle (Table 2).

The proportion of correct answers was significantly higher among the students of health sciences than among those who participated in other studies: $86.0 \%, 71.5 \%$ and $61.1 \%$ vs. $71.9 \%, 59.8 \%$ and $43.2 \%$ in Serbia, Hungary and Romania, respectively. More than a quarter of the Romanian students of other faculties (26.3\%) thought that they could become pregnant at any time within a menstrual cycle. 


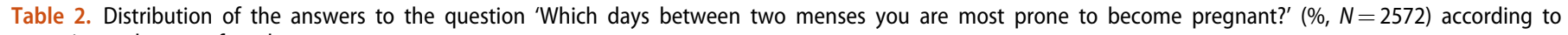
countries and types of study.

\begin{tabular}{|c|c|c|c|c|c|c|}
\hline \multirow[b]{2}{*}{ Presumed fertile period of the cycle } & \multicolumn{2}{|c|}{ Hungary } & \multicolumn{2}{|c|}{ Serbia } & \multicolumn{2}{|c|}{ Romania } \\
\hline & $\begin{array}{l}\text { Health sciences } \\
\qquad(N=277)\end{array}$ & $\begin{array}{c}\text { Other } \\
(N=291)\end{array}$ & $\begin{array}{l}\text { Health sciences } \\
\qquad(N=408)\end{array}$ & $\begin{array}{c}\text { Other } \\
(N=490)\end{array}$ & $\begin{array}{l}\text { Health sciences } \\
\qquad(N=463)\end{array}$ & $\begin{array}{c}\text { Other } \\
(N=643)\end{array}$ \\
\hline At the beginning & 8.3 & 9.6 & 2.7 & 4.7 & 11.4 & 13.4 \\
\hline At the middle & $71.5^{* *}$ & 59.8 & $86.0^{* * *}$ & 71.8 & $61.1 * * *$ & 43.2 \\
\hline At the end & 7.2 & 11.3 & $3.7^{* * *}$ & 12.0 & $8.0^{* *}$ & 14.0 \\
\hline Whenever & $6.9^{*}$ & 13.1 & $5.9^{*}$ & 9.8 & $16.4^{* * *}$ & 26.3 \\
\hline Missing answer & 6.1 & 6.2 & 1.7 & 1.6 & 3.0 & 3.1 \\
\hline Total & 100.0 & 100.0 & 100.0 & 100.0 & 100.0 & 100.0 \\
\hline
\end{tabular}

Significant difference in study type comparisons within each country: $p<.05, * *<.01, * * * p<.001$.

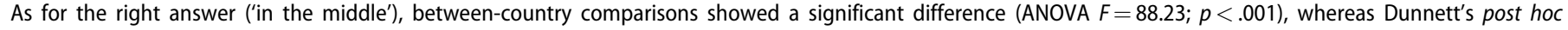
test showed that all pair-wise country comparisons proved to be significant.

After dichotomisation of the answers (1 point for the correct answer and 0 for wrong ones), two-way ANOVA was applied to reveal both country- and study-type effects.

It showed that the country of origin had a significant, medium-level role in the answer patterns $\left(\eta^{2}=6.3 \%\right)$, and the type of study had a significant but small effect $\left(\eta^{2}=2.5 \%\right)$. These two factors proved to be independent of each other ( $p=.41$ for the interaction).

Other background variables seemed to have only limited effect on the answers to the question about the nature and length of the fertile period, namely type of permanent residency and marital status, $1.9 \%$ and $1.6 \%$ in Hungary, $0.4 \%$ and $0.3 \%$ in Serbia, $0.3 \%$ and $0.5 \%$ in Romania, respectively $\left(\eta^{2}, N=2572\right)$. The length of the periods and spotting between two cycles showed even less influence on the answers (Hungary: $0.1 \%$ and $0.0 \%$, Serbia: $0.0 \%$ and $0.3 \%$ and Romania: $0.9 \%$ and $0.4 \% ; \eta^{2}, N=2572$ ).

\section{Attitudes towards menstruation}

Three questions examined the attitudes towards menstruation: whether students consider monthly menstruation to be an important condition for health; their attitudes to the preferred frequency of menstruation; and their attitudes towards menstruation from the aspect of whether they would use a safe oral contraceptive in order to suppress menstruation as long as needed without serious adverse or side-effects. Table 3 presents the answer patterns related to these questions.

The great majority of female university students considered monthly menstruation necessary in order to be healthy (Table 3(a)). Both the country of origin and the nature of the university studies had significant effects on the answers with contingency coefficients of $0.16(p<.001)$ and $0.05(p=.048)$, respectively.

Several other questions concerned the preferred frequency of menstruation (Table 3(b)). The contingency coefficients revealed large differences between the countries regarding the preferred frequency of menstruation (contingency coefficient $=.27, p<.001$ ), while the nature of the university studies had a non-significant effect (contingency coefficient $=0.05, p=.19$ ).

Many university students would be interested in an oral contraceptive that suppresses menstruation for as long as desired (Table 3c). There were relevant differences between the countries (contingency coefficient $=0.27, p<.001$ ), and the nature of the university studies had a significant effect on the answers (contingency coefficient $=0.06, p=.02$ ).

\section{Connections between cycle characteristics, knowledge and attitudes}

The eta-squared values (explained variance) of several personal characteristic background variables related to the trivial knowledge item concerning the fertile period within the menstrual cycle indicated that students with regular or longer cycles were more aware of the existence and characteristics of the fertile period within a menstrual cycle. Similarly, students who had been on the sick-leave because of menstruation-related symptoms, and especially those who used hormonal contraceptives (eta-squared $=1.2 \%$ ), had better knowledge of the fertile period. Nevertheless, only $60 \%$ of the students who used the calendar method of contraception gave the correct answer to the question of the fertile period in the cycle.

In the search for an explanation for attitude-related variables, the preferred frequency of menstruation was correlated with personal characteristics. Two variables proved to display significant correlations with the preferred frequency: having any disorder in the past (Spearman's rho $=0.04$ ) and having been on sick-leave because of symptoms during menstruation (Spearman's rho $=0.07$ ). The students' interest in a daily, low-dose, continuously used hormonal combined oral contraceptive, which may suppress menstruation for as long as desired, had a significant Spearman's rho correlation with the preferred frequency of menstruation (0.17).

\section{Discussion}

As expected, the nature of the university study had a significant effect on the knowledge of the fertile period in the cycle: the proportion of correct answers was higher among the students of health sciences by $14.1 \%, 11.7 \%$ and $17.9 \%$ in Serbia, Hungary and Romania, respectively. However, the country of origin (reflecting different historical and cultural factors) proved to be a stronger influencing factor than the nature of university studies. These findings are in accordance with the results of Capuano et al. (2009). Other personal background variables (including the type of permanent residence, the marital status, the length of the periods and spotting between cycles) had limited effects on whether the 
Table 3. Attitudes towards menstruation (\%, N=2572).

\begin{tabular}{|c|c|c|c|c|c|c|}
\hline \multirow[b]{2}{*}{ Answer options } & \multicolumn{2}{|l|}{ Hungary } & \multicolumn{2}{|c|}{ Serbia } & \multicolumn{2}{|c|}{ Romania } \\
\hline & Health sciences $(N=277)$ & Other $(N=291)$ & $\begin{array}{l}\text { Health sciences } \\
\qquad(N=408)\end{array}$ & Other $(N=490)$ & Health sciences $(N=463)$ & Other $(N=643)$ \\
\hline \multicolumn{7}{|c|}{ 3(a). 'Do you think it is necessary to have a period every month to be healthy?' } \\
\hline Yes & 73.3 & 58.4 & 69.6 & 72.4 & 74.5 & 70.9 \\
\hline No & 8.3 & 19.2 & 4.4 & 2.2 & 10.8 & 8.2 \\
\hline No opinion & 16.6 & 22.3 & 25.0 & 24.7 & 12.7 & 19.6 \\
\hline Missing answer & 1.8 & 0.0 & 1.0 & 0.6 & 1.9 & 1.2 \\
\hline Total & 100.0 & 100.0 & 100.0 & 100.0 & 100.0 & 100.0 \\
\hline \multicolumn{7}{|c|}{$\begin{array}{l}\text { Both the country (contingency coefficient }=0.164 ; p<.001 \text { ) and the type of the study (contingency coefficient }=0.049 ; p=.048 \text { ) had a significant effect on the } \\
\text { answer patterns, respectively. }\end{array}$} \\
\hline \multicolumn{7}{|c|}{ 3(b). 'What is the preferred frequency of menstruation?' } \\
\hline Once a month & 28.5 & 25.1 & 27.7 & 24.1 & 36.5 & 39.2 \\
\hline 3 monthly & 31.0 & 36.1 & 10.8 & 12.2 & 15.8 & 18.5 \\
\hline 6 monthly & 5.8 & 8.2 & 6.9 & 8.2 & 7.1 & 8.6 \\
\hline Once a year & 10.5 & 5.2 & 13.0 & 13.1 & 13.2 & 12.0 \\
\hline Never & 23.5 & 24.1 & 41.2 & 42.2 & 26.3 & 21.0 \\
\hline Missing answer & 0.7 & 1.4 & 0.5 & 0.2 & 1.1 & 0.8 \\
\hline Total & 100.0 & 100.0 & 100.0 & 100.0 & 100.0 & 100.0 \\
\hline \multicolumn{7}{|c|}{$\begin{array}{l}\text { The country of origin had a significant effect on the answer patterns (contingency coefficient }=0.267 ; p<.001 \text { ), whereas the type of the study did not (contin- } \\
\text { gency coefficient }=0.049 ; p=.19 \text { ). }\end{array}$} \\
\hline \multicolumn{7}{|c|}{$\begin{array}{l}\text { 3(c) 'Would you use a daily, low-dose combined oral contraceptive without a pill-free interval to suppress menstruation for as long as you needed, knowing tha } \\
\text { this would not have harmful effects?' }\end{array}$} \\
\hline Yes & 37.5 & 44.3 & 55.6 & 60.2 & 59.4 & 60.2 \\
\hline No & 51.6 & 50.5 & 20.1 & 20.8 & 25.3 & 23.2 \\
\hline On special occasions & 5.4 & 2.4 & 18.9 & 11.6 & 9.3 & 9.2 \\
\hline Missing answer & 5.4 & 2.7 & 5.4 & 7.3 & 6.3 & 7.5 \\
\hline Total & 100.0 & 100.0 & 100.0 & 100.0 & 100.0 & 100.0 \\
\hline
\end{tabular}

'On special occasions' usually referred to vacation or summer time.

respondents had an appropriate factual knowledge about the fertile interval in the menstrual cycle in comparison with the effects of the nationality and the nature of the university studies (Hampton and Mazza 2015).

Approximately 60 to $75 \%$ of the students believed that the monthly bleeding is required for health. There were only small differences $(<5 \%)$ between students of health sciences and students of other faculties in this respect, except in Hungary, where $14.9 \%$ more students of health sciences had that view than students of other disciplines. Our results are similar to the findings of Swedish and Italian studies (Tyden et al. 2006; Fruzetti et al. 2008).

The outcome of the question concerning the preferred frequency of menstruation was rather surprising (Table 3(b)). The monthly cycle was the most acceptable among the Romanian students: $36.5 \%$ and $39.2 \%$ for those engaged in health sciences and other faculties, respectively. In contrast, slightly fewer students of other faculties than students of health sciences preferred a monthly period in the other two countries: $\sim 25 \%$ vs. $\sim 28 \%$. These results are in line with the findings that only $37 \%$ of Swiss and $32 \%$ of Italian women 'prefer to bleed monthly' (Fruzetti et al. 2008; Merki-Feld et al. 2014). Furthermore, around 20 to $25 \%$ of the students would prefer no menstruation at all, except in Serbia, where the proportion was slightly more than $40 \%$. The likely explanations for the low rate of students desire to bleed monthly (as low as around $30 \%$ ) could be the related decrease in premenstrual syndrome, and the belief that sexual intercourse is forbidden during bleeding days, similarly to the results described in the paper by Kaunitz (Kaunitz 2000; Vollmer \& van der Spuy 2016).

A daily, low-dose combined oral contraceptive without a pill-free interval was less acceptable among Hungarian students of health sciences and students of other faculties, with proportions of $37.5 \%$ and $44.3 \%$, respectively, as compared with 55 to $60 \%$ in the other two countries. Similarly, significantly fewer Hungarian students would use it even on special occasions, such as while travelling or on holiday (Table 3c). However, women who report serious complaints about menstruation would choose fewer periods in order to reduce these problems (Archer 2006; Lin \& Barnhart 2007, de Silva-Filho et al. 2016), e.g. a study by Tonkelaar and Oddens has found that menstruating women using combined oral contraceptives preferred less painful or less heavy periods (den Tonkelaar and Oddens 1999). The limitation of that study is that only the oral combined contraceptive method has been mentioned during the survey, since other long-acting hormonal methods were not available at the time of the study. Further investigations are needed to evaluate the attitude towards long-acting hormonal contraceptive methods (e.g. injections, the IUD or vaginal rings). An investigation among adolescent females by Eke has revealed the need for proper sexual education on long-acting reversible contraception (Eke \& Alabi-Isama 2011).

One of the limitations of the questionnaire methodology is the diverse response rate. The authors are aware of that there are several 'sensitive' questions to which an honest answer may cause frustration or the feeling of being offended. Therefore, in each step of the analysis, the number of valid data was indicated. If we had decided to restrict each analysis to the subsample with no missing values at all, the analyses would have been conducted on about half of the whole sample. Fortunately, by exploring the relevant and 
meaningful pairwise connections, fairly large and still representative samples could be studied.

The general knowledge on the menstrual cycle, and especially on the fertile period, should be increased for at least two reasons: (1) to prevent unintended pregnancies in the event of the use of a less effective contraceptive method, and (2) to provide knowledge for the planning of a desired pregnancy. Proper education is not only important to encourage young people to practice safe sex (Orji \& Esimai 2005) to prevent unintended pregnancies, but to prevent sexually transmitted infections as well. Some African studies have revealed that intervention studies increase the knowledge of adolescents (Mba et al. 2007; Mphatswe et al. 2016).

Since merely 25 to $40 \%$ of the participants preferred monthly menstruation, the use of a long-acting low-dose hormone-releasing contraceptive method (e.g. an injection, an intrauterine systems or a vaginal ring) could be an optimal method for contraception, and these methods are less userdependent, which is also an important aspect in the young generation. In Hungary, the intrauterine device had not been recommended for nulliparous women, but the recommendation has been changed recently (Major 2014). These safe and effective contraceptive methods maintain fertility, and are in accordance with enhanced environmental consciousness, which is the interest of not only healthcare providers, but young women themselves as the mean age at first childbirth increased in this region.

In conclusion, merely $71.5 \%$ and $59.8 \%$ of the Hungarian, $86 \%$ and $71.8 \%$ of the Serbian and $61.1 \%$ and $43.2 \%$ of the Romanian students of health sciences and students of other faculties had proper knowledge on the fertile period within a menstrual cycle.

Monthly bleeding was desired by merely $30-40 \%$ of the university students questioned, and a low-dose combined oral contraceptive without a pill-free interval would be used by $40-60 \%$ of them. In spite of this, a monthly period was considered to be necessary for their health by approximately $60-75 \%$ of them. This questionnaire-based study considered the potential use of a low-dose combined pill, and further studies should be conducted on newly developed green contraceptive methods.

\section{Disclosure statement}

The authors report no conflict of interest.

\section{Funding}

The study was funded by the European Society of Contraception and Reproductive Health.

\section{References}

Archer DF. 2006. Menstrual-cycle-related symptoms: a review of the rationale for continuous use of oral contraceptives. Contraception 74:359-366.
Bjelica A. 2008. Socio-demographic factors influence contraception use among female students of the University of Novi Sad (Serbia). European Journal of Contraception Reproductive Health Care $13: 422-430$.

Capuano S, Simeone S, Scaravilli G, Raimondo D, Balbi C. 2009. Sexual behaviour among Italian adolescents: Knowledge and use of contraceptives. European Journal of Contraception Reproductive Health Care 14:285-289.

den Tonkelaar I, Oddens BJ. 1999. Preferred frequency and characteristics of menstrual bleeding in relation to reproductive status, oral contraceptive use, and hormone replacement therapy use. Contraception 59:357-362.

Eurostat. 2015. Employment, Social Affairs \& Inclusion Eurostat Demography Report. Available from: http://ec.europa.eu/eurostat/ documents/3217494/7018888/KS-HA-15-001-EN-N.pdf/6f0d4095-5e7a4aab-af28-d255e2bcb395

Eke AC, Alabi-Isama L. 2011. Long-acting reversible contraception (LARC) use among adolescent females in secondary institutions in Nnewi. Nigeria. Journal of Obstetrics and Gynaecology 31:164-168.

Fruzetti F, Paoletti AM, Lombardo M, Carmignani A, Genazzani AR. 2008. Attitudes of Italian women concerning suppression of menstruation with oral contraceptives. European Journal of Contraception Reproductive Health Care 13:153-157.

Inandi T, Tosun A, Guraksin A. 2003. Reproductive health: knowledge and opinions of university students in Erzurum, Turkey. European Journal of Contraception and Reproductive Health Care 8:177-184.

Hampton K, Mazza D. 2015. Fertility-awareness knowledge, attitudes and practises of women attending general practise. Austrailian Family Physician 44:840-5.

Kaunitz AM. 2000. Menstruation: choosing whether and when. Contraception 62:277-284.

de Silva-Filho AL, Lira J, Rocha AL, Ferreira MC, Lamaita RM, Cândido EB, Carneiro MM. 2016. Non-hormonal and hormonal intrauterine contraception: survey of patients' perceptions in four Latin American countries. European Journal of Contraception and Reproductive Health Care 21:213-219.

Lin K, Barnhart K. 2007. The clinical rationale for menses-free contraception. Journal of Women's Health 16:1171-1180.

Major T. 2014. Intrauterine devices for nulliparous women: commitment of the Board of Assisted Reproduction of the Hungarian College of Obstetrics and Gynaecology. Accepted by the Council and Board of the Hungarian College of Obstetrics and Gynaecology on 13 June.

Mba Cl, Obi SN, Ozumba BC. 2007. The impact of health education on reproductive health knowledge among adolescents in a rural Nigerian community. Journal of Obstetrics and Gynaecology 27:513-517.

Mphatswe W, Maise H, Sebitloane M. 2016. Prevalence of repeat pregnancies and associated factors among teenagers in KwaZulu-Natal, South Africa. International Journal of Gynecology and Obstetrics 133:152-155.

Merki-Feld GS, Breitschmid N, Seifert B, Kreft M. 2014. A survey on Swiss women's preferred menstrual/withdrawal bleeding pattern over different phases of reproductive life and with use of hormonal contraception. European Journal of Contraception Reproductive Health Care 19:266-275.

Orji EO, Esimai OA. 2005. Sexual behaviour and contraceptive use among secondary school students in Ilesha South West Nigeria. Journal of Obstetrics and Gynaecology 25:269-272.

Tyden T, Skoog Svanberg A, Karlström PE, Lihoff L, Lampic C. 2006. Female university students' attitudes to future motherhood and their understanding about fertility. European Journal of Contraception Reproductive Health Care 11:181-189.

Vollmer LR, van der Spuy ZM. 2016. Contraception usage and timing of pregnancy among pregnant teenagers in Cape Town, South Africa. International Journal of Gynecology and Obstetrics 133:334-337. 